\title{
Investigating the Energy and Thermal Implications of Installation of an Air Curtain and an Automatic Door in Convenience Stores in Wales
}

\author{
Shan Shan Hou ${ }^{1}$, Joanne Patterson ${ }^{1}$, Xiaojun $\mathrm{Li}^{1}$, Emmanouil Perisoglou ${ }^{1}$, Phil Jones ${ }^{1}$ \\ ${ }^{1}$ Cardiff University, Cardiff, United Kingdom
}

\begin{abstract}
A convenience store is a common building type in Wales, which has potential to achieve carbon emissions reduction through practical retrofit strategies. However, there is a lack of studies conducted to address the low carbon retrofit for these convenience stores.
\end{abstract}

Easy access into a convenience store is essential, however an open entrance will allow uncontrolled external air entering the internal space. During heating seasons, this results in difficult to heat spaces due to cold external air freely penetrating and leaving the heating premises. A significant amount of energy is wasted to heat up a large volume of cold air that enters through an open entrance and escapes from it soon after. In addition, the penetrating external air can cause cold draft and lead to discomfort for the space users, including store staff and customers.

This paper presents a modelling-led approach to investigate the energy and thermal performance of two practical strategies to reduce heat losses through an open entrance in a typical convenience store in Wales. The two strategies explored are the installation of an air curtain over an open entrance and the replacement of an open entrance with an automatic door.

Integrated building and air flow simulations which link air infiltration and ventilation estimation with building energy and thermal simulation will be applied to examine the energy and thermal implication of the two strategies. HTB2 which is a dynamic building energy and thermal package, and Winair which is an air flow package; will be used in this study.

This research will identify the energy and thermal implications of installation of an air curtain and an automatic door in the typical convenience store. Monthly and annual energy consumption, and room temperature for three cases will be predicted by a series of integrated building and air flow simulations. The benefits that an air curtain and an automatic door can provide will be evaluated and compared, in relation to energy consumption, as well as the improvement of the thermal environment. In addition, the associated capital and operational cost of the two approaches will be discussed.

\section{Introduction}

The global construction industry is in a transition period of reducing energy consumption and carbon emissions. Energy management has become a top priority in the success and sustainability of all types of buildings. More and more convenience stores across UK high streets start committing to energy efficiency and reducing operational costs. The main energy reduction strategies focus on refrigeration and lighting systems. However, few strategies address the reduction of heat losses through a frequently used main entrance in the UK during winter time. There are two common methods to reduce heat loss through opening doors (Figure 1).

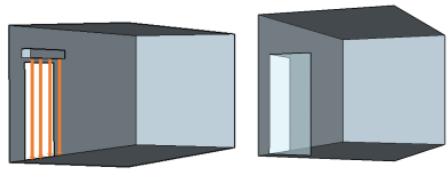

Figure 1: Illustration of air curtain (left) and automatic swing door (right).

Using an air curtain can create a controlled stream of air and direct it across the full width and height of an opening to create an energy saving air seal. This seal separates different environments, allowing a smooth, unhindered flow of traffic and unobstructed vision through the opening. An air curtain is not intended to replace a physical door but to serve as an energy savings device by creating an invisible barrier when the physical door is open since an air curtain can help to contain heated or airconditioned air, provide sizeable energy savings and personal comfort in both industrial and commercial settings. On the other hand, an automatic door can reduce the amount of air infiltration and improve energy efficiency by only staying open when a customer entering or leaving the store.

Few independent references can be found specifically looking at the application of an air curtain or an automatic door in relation to their energy savings. Air curtains can save up to $30 \%$ on running costs, according to findings 
from the Carbon Trust and Bristol University, and a recent study by the Carbon Trust for ECA purposes showed that up to half of the 1.3 million commercial buildings in the UK could benefit from this technology. When specified correctly, air curtains can offer a short payback time as low as five months (Dimplex, 2013). Berner International Corporation (Berner International Corporation, 2008) suggested that energy saved by using air curtains can range from $1 \%-10 \%$, depending on climate, building size and traffic volume with a generally payback period for the equipment and installation within 1-3 years. A case study of a McDonald's store in Milton Keynes with an air curtain showed a saving of $59 \mathrm{kWh}$ per day in energy consumed compared to a store in Stoke without an air curtain - equating to a direct saving in energy of $£ 6.20$ per day (Mitsubishi Electric, 2015). A study conducted by Wang (Wang, 2013) showed that whole building annual energy use can be reduced when an air curtain is installed in all the climate zones in the US. The major saving of the air curtain door mainly comes from the heating saving, and better performance will be achieved for colder climate. In relation to draft lobbies, a good practice guide suggested draft lobbies or recessed entrances should be used to avoid excessive heat loss at door way without any further indication on how much energy could be saved (BRECSU and ETSU, 1996).

Therefore, this paper aims to investigate energy and thermal implications of installation of an air curtain and an automatic door in convenience stores in the UK, using a modelling-led approach.

\section{Research methodology}

\section{Integrated building and air flow simulation}

This study applies an integrated building and airflow simulation which link air infiltration and ventilation estimation with building thermal simulation. When these two models are conflated, the potential of analysis of ventilation, infiltration, gradients of comfort conditions, as well as dispersion of pollutants is contemplated (Negrao, 1995). In this study, a building energy simulation model is established to predict the energy consumption with the air change rate input from an airflow simulation. In addition, the airflow simulation predicts indoor comfort as well.

HTB2, a dynamic building energy model developed at the Welsh School of Architecture (Cardiff University), is used in this study. Based on weather data, building construction and layout details, shading masks, building services, and occupation profiles for people, equipment and lighting, it can simulate hourly internal thermal conditions (air temperatures and surface temperatures), as well as annual energy consumption. It has undergone extensive testing, validation, including the IEA Annex 1 (Faber, 1980) IEA task 12 (Lomas, 1994), the IEA BESTEST (Neymark et al., 2011).
Winair, a CFD model developed as a research tool at the Welsh School of Architecture (Cardiff University), is applied to be integrate with HTB2 in this study. It is an iterated process. Winair predicts air change rates through the opening door with the application of an air curtain and an automatic door with the calculated thermal condition from HTB2. These predicted air change rates are input into HTB2 building energy simulation to calculate associated indoor thermal condition. This indoor thermal condition is then used by Winair to predict related air change rate. The iteration goes on until the predicted air change rates and the internal thermal conditions are matched.

\section{Research steps}

This study is conducted in three steps: 1) select a typical design of convenience store, located in the UK; 2) conduct a detailed survey of the shop to develop modelling frameworks for current practice, as well as for the alternatives with installation of an air curtain and an automatic door to reduce heat loss through entrance opening, including parameters for internal gains, building fabric, and HVAC systems; 3) conduct integrated building and air flow simulations for (i) current practice, (ii) with an air curtain, and (iii) with an automatic door. The simulation results of monthly and annual energy consumption are compared and discussed.

\section{Building simulation}

\section{A typical convenience store}

Deri post office located in Mid Glamorgan, a typical convenience store in the UK, was chosen for this study (Figure 2). It occupies the ground floor of a terrace house, with a total area of $56.3 \mathrm{~m}^{2}$, and a floor to ceiling height of $2.3 \mathrm{~m}$. The first floor is the living space for the shop owner. This study focused on the store entrance on the ground floor.

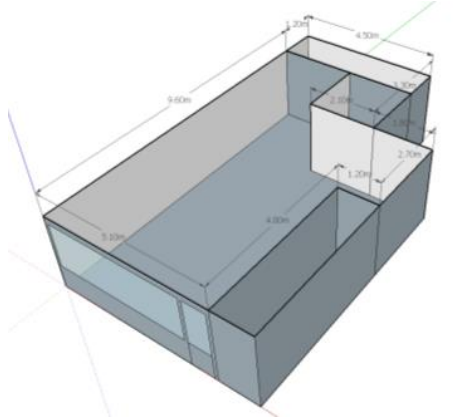

Figure 2: Typical convenience store floor plan.

\section{Simulation frameworks}

A detailed survey was conducted for Deri post office. In addition, carbon dioxide concentration decay tests were carried out to determine the air change rates when the 
entrance door open and closed. The reason carbon dioxide was chosen as the tracer gas is its low risk and cost. Table 1 shows the simulation framework for the current practice.

Table 1: Simulation framework for the current practice.

\begin{tabular}{|c|c|}
\hline \multicolumn{2}{|c|}{ Fabric efficiency U-value $\left(\mathrm{W} / \mathrm{m}^{2} / \mathrm{K}\right)$} \\
\hline External wall & $\begin{array}{c}1.56 \text { (cavity wall without } \\
\text { insulation)_ }\end{array}$ \\
\hline Ceiling & 0.95 \\
\hline Ground floor & 0.35 \\
\hline Glazing & $\begin{array}{c}2.8 \text { (double glazing with PVC } \\
\text { frame), } \mathrm{G}=64 \%\end{array}$ \\
\hline \multicolumn{2}{|r|}{ Internal gains $\left(\mathrm{W} / \mathrm{m}^{2}\right)$} \\
\hline Lighting & $21.5 \mathrm{~W} / \mathrm{m}^{2}$ \\
\hline Plug load & $39.3 \mathrm{~W} / \mathrm{m}^{2}$ \\
\hline Occupancy gain & 2 people \\
\hline Operation time & $\begin{array}{l}\text { Monday-Friday: 07:00 to } 19: 00 \\
\text { Saturday: 08:00 to } 19: 00 \\
\text { Sunday: 08:00 to } 13: 00\end{array}$ \\
\hline \multicolumn{2}{|c|}{ Air change rate $(\mathrm{ac} / \mathrm{h})$} \\
\hline Doors open & $3.6 \mathrm{ac} / \mathrm{h}$ \\
\hline Doors closed & $0.3 \mathrm{ac} / \mathrm{h}$ \\
\hline Door open times & $\begin{array}{l}40 \text { times/ hour during operational } \\
\text { time ( } 20 \text { people entering and } \\
\text { leaving the store) } \\
\text { The store opens } 46 \text { hours a week } \\
\text { and } 50 \text { weeks } \\
\text { The air curtain is operating for } 15 \mathrm{~s} \\
\text { per opening time, while the } \\
\text { automatic door opens for } 15 \mathrm{~s}(5 \mathrm{~s} \\
\text { opening time, } 5 \mathrm{~s} \text { stay open and } 5 \mathrm{~s} \\
\text { closing time) }\end{array}$ \\
\hline \multicolumn{2}{|r|}{ Systems } \\
\hline $\mathrm{AC}$ & $\mathrm{COP}=2$ \\
\hline \multicolumn{2}{|r|}{ Climate condition } \\
\hline Weather data & Cardiff typical year \\
\hline Wind condition & Windless \\
\hline \multicolumn{2}{|c|}{$\begin{array}{l}\text { Notes: } \\
\text { The designed room temperature used in the simulation } \\
\text { is } 19-21^{\circ} \mathrm{C} \text { (winter) to } 21-25^{\circ} \mathrm{C} \text { (summer) (CIBSE, } \\
2016 \# 55 \text { ). } \\
\text { The real condition is an AC unit is used for } 4 \mathrm{hrs} \text { per } \\
\text { day from December to April when air temperature is } \\
\text { lower than } 13^{\circ} \mathrm{C} \text {; and for } 3 \mathrm{hrs} \text { per day, } 15 \text { days in } \\
\text { summer. In addition, a } 5 \mathrm{~kW} \text { Resistive heater is used } \\
5 \mathrm{hrs} \text { per day during winter time. }\end{array}$} \\
\hline
\end{tabular}

\section{Simulation cases}

Three cases were explored:
1) The base case which is the current practice: entrance door opens during the working hours.

2) The case with a surface mounted over door air curtain installed in the internal side of the entrance: the air curtain is switched on when entrance door is open, with air flow rate at $1250 \mathrm{~m}^{3} / \mathrm{h}$ at 25 degrees input (Figure 3 ). The simulated air curtain was modelled as being fitted properly with the air stream could reach the floor and no gaps at either side of the door which allow draughts to enter.

3) The case with an automatic door designed at the entrance: the door only opens when a customer is entering or leaving the store (Figure 4).

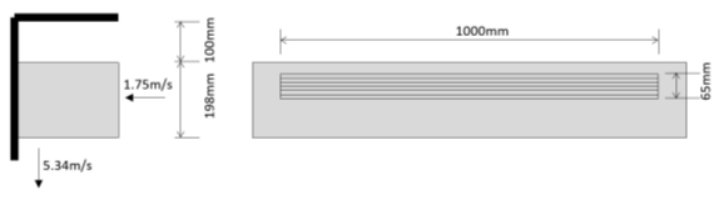

Figure 3: Details of the air curtain.

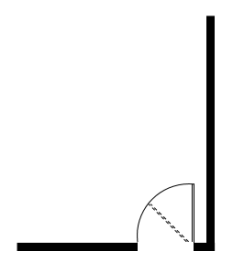

Figure 4: Details of the automatic door.

\section{Results and discussion}

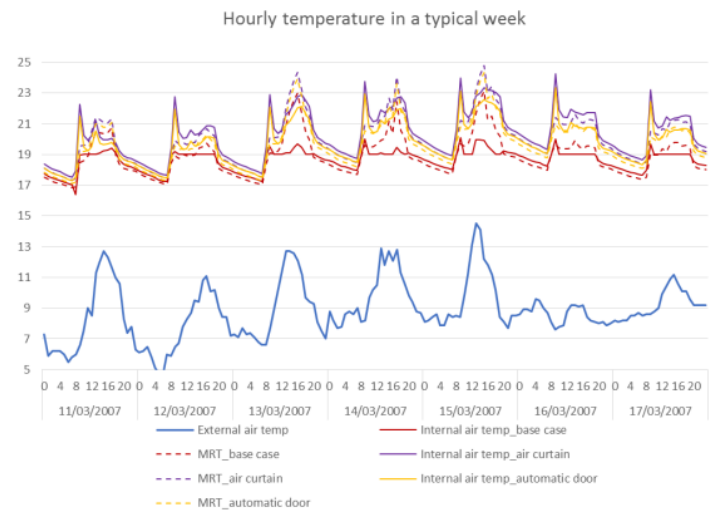

Figure 5: Comparison of temperatures in three cases.

The simulation results (Figure 5) suggest that the average air temperature, for the base case, in the main occupied area is 18.0 degree, which match with the monitored data. When external air temperature is 11.0 degree, the internal air temperature is 17.9 degrees in the survey.

With an air curtain, the simulation results suggest that, the temperature distribution inside the store is uniform in both 
horizontal and vertical dimensions. The average air temperature can reach 24 degrees.

The power consumption of an air curtain is $9 \mathrm{~kW}$ which include the fun power at $0.5 \mathrm{~kW}$. The annual energy consumption is $1800 \mathrm{kWh}$.

With an automatic door, the simulation results suggest that, the temperature distribution inside the store is more uniform than the base case where the main entrance is open. The average air temperature can reach 22 degrees.

A typical single swing door operator cost is $£ 1850$. The power consumption is $50 \mathrm{~W}$. The annual energy consumption of the automatic door is $20 \mathrm{kWh}$.

\section{The base case}

Figure 6 shows the air temperature and air speed at counter height in the store plan. Figure 7 and 8 show the air temperature and air movement distribution in both sections.

The air temperature distribution is not uniform. The air temperature at the entrance at the lower level remains as low as external air temperature at 11 degrees. The air temperature in the space away from the entrance can reach 19 degrees.

During the windless case, the warmer air from inside of the store escapes from the top half of the opening entrance, while the negative pressure drives external cold air entering the store through the bottom half of the main door. The canal effect makes the air speed accelerate and reach the maximum air speed at $0.47 \mathrm{~m} / \mathrm{s}$ at the ground level.

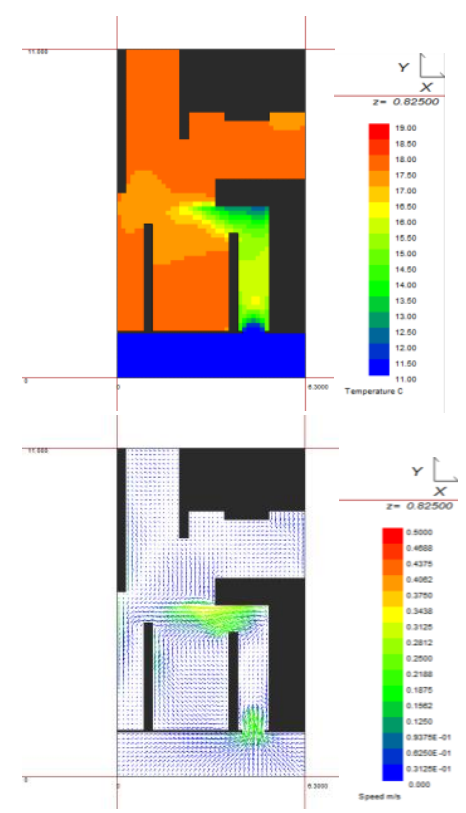

Figure 6: Base case_air temperature and air speed at counter height.

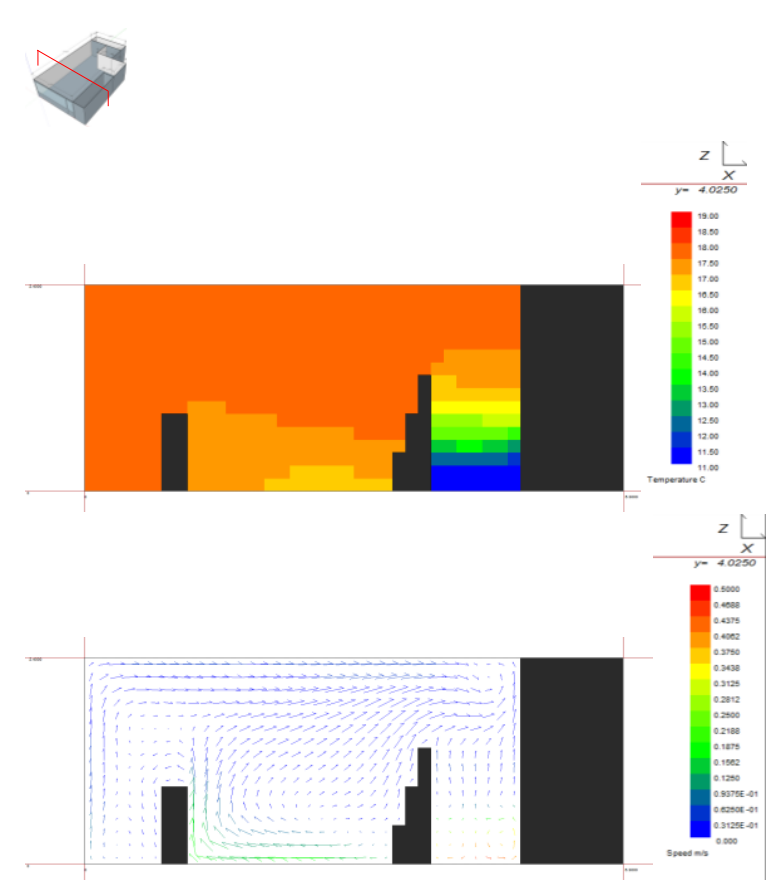

Figure 7: Base case_air temperature and air speed distribution in the cross section.

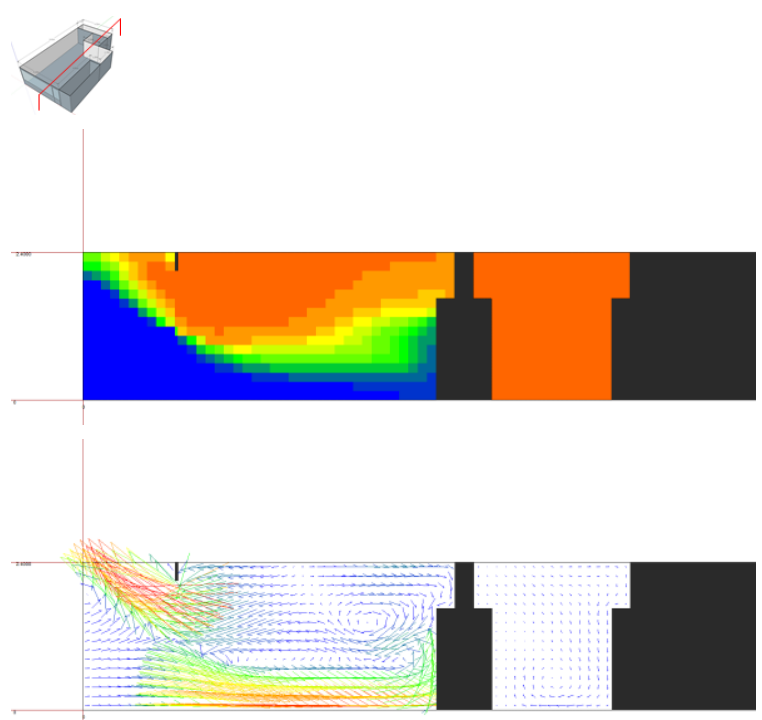

Figure 8: Base case_air temperature and air speed distribution in the section cross the entrance.

\section{The air curtain case}

Figure 9 shows the air temperature and air speed at counter height in the store plan. Figure 10 and 11 show the air temperature and air movement distribution in both sections. 


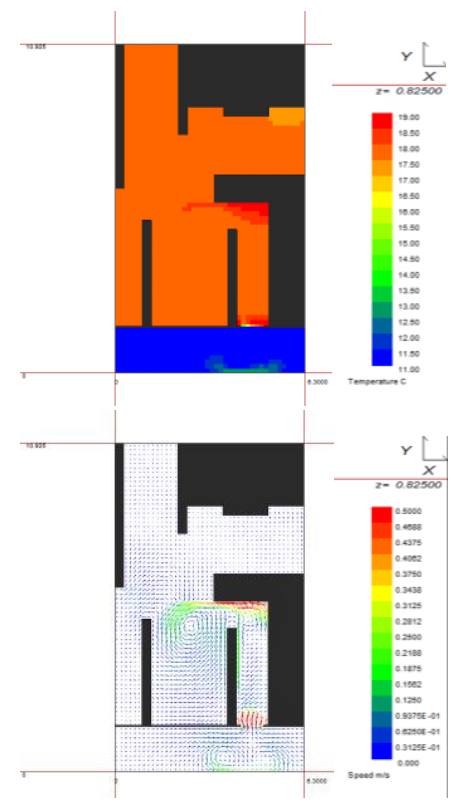

Figure 9: Air curtain case _ air temperature and air speed at counter height.

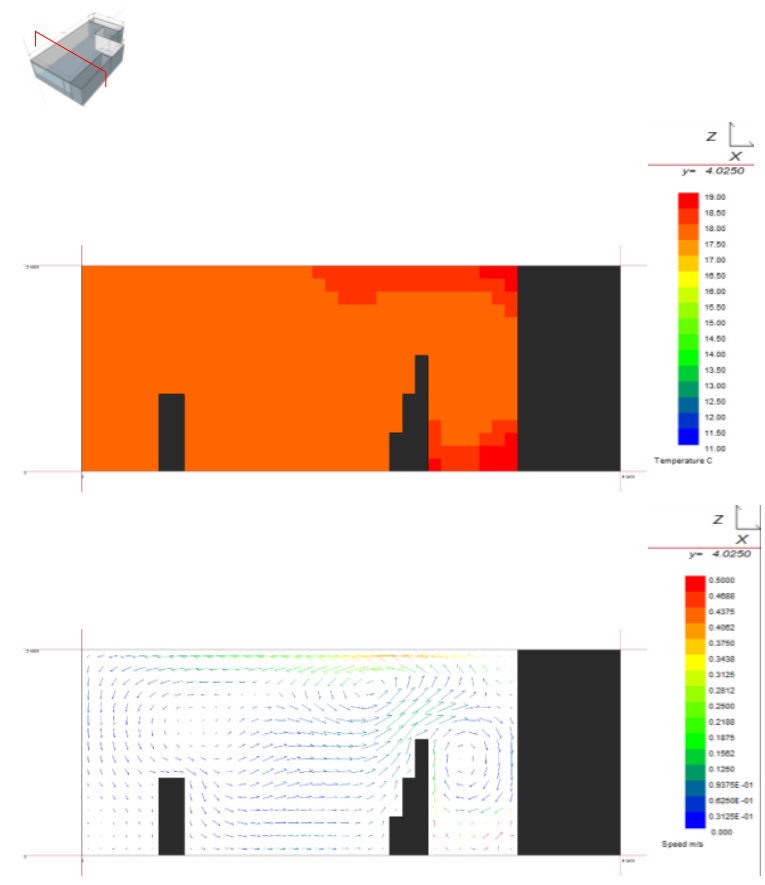

Figure 10: Air curtain case_air temperature and air speed distribution in the cross section.

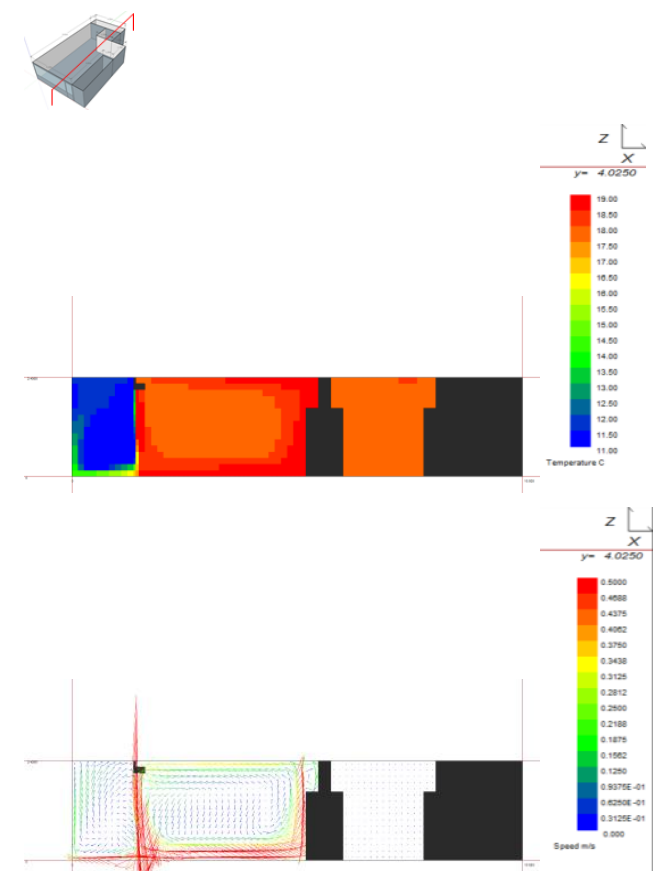

Figure 11: Air curtain case_air temperature and air speed distribution in the section cross the entrance.

\section{The automatic door case}

Figure 12 shows the air temperature and air speed at counter height in the store plan. Figure 13 and 14 show the air temperature and air movement distribution in both short and long sections.

Cold external air can still penetrate into the internal space during the door opening time. But the shorter opening time allows cold air to be warmed up around the entrance and reduces the amount of warm air escaping from the internal space.

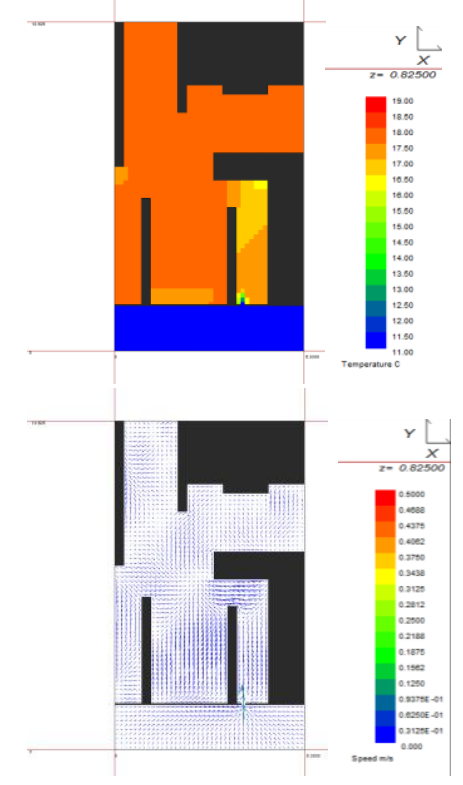


Figure 12: Automatic door case_air temperature and air speed at counter height.

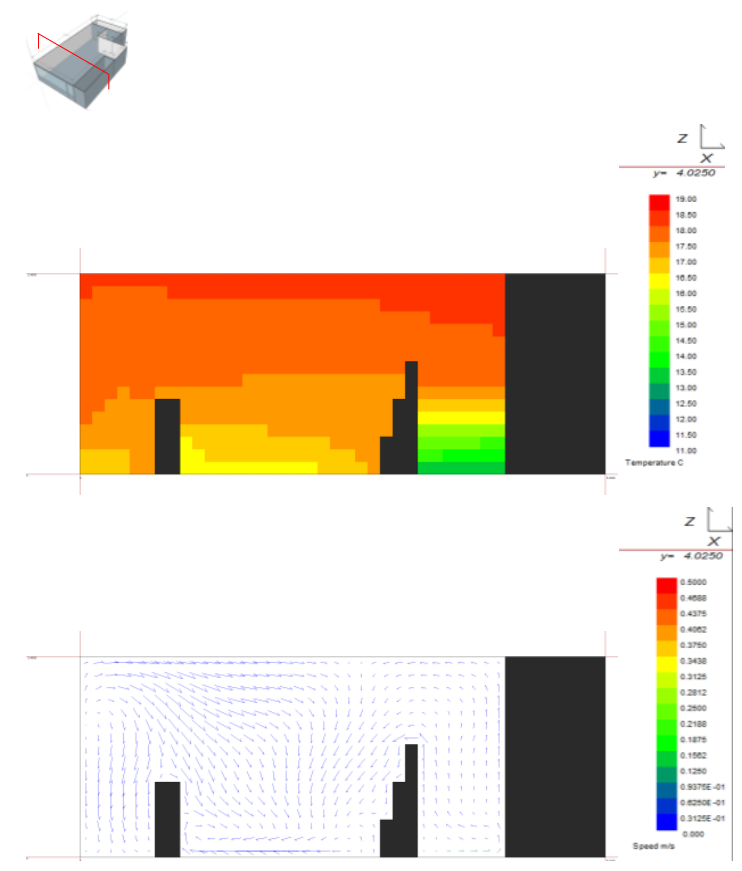

Figure 13: Automatic door case_air temperature and air speed distribution in the cross section.

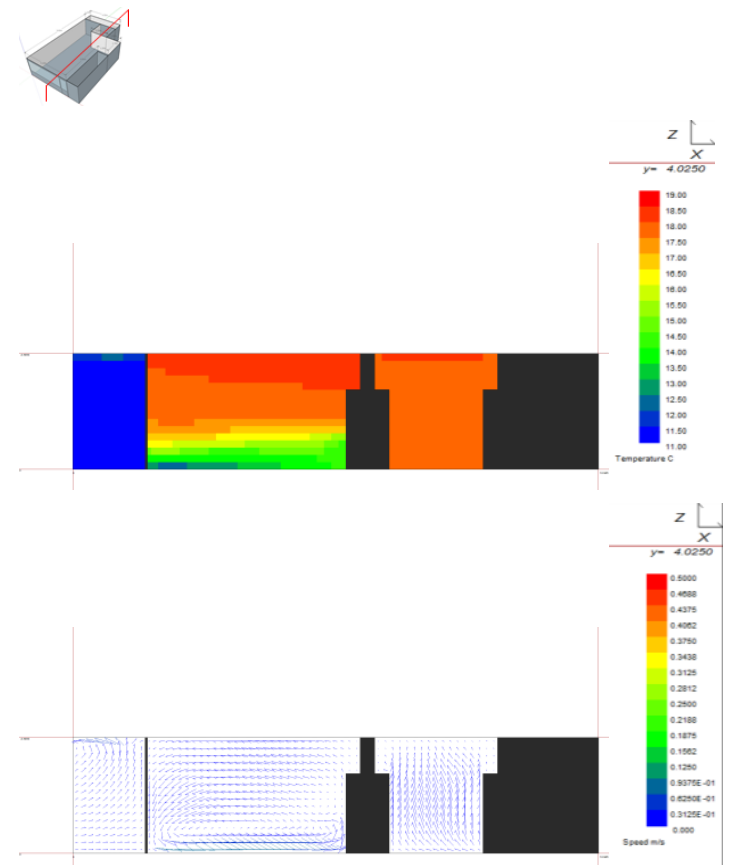

Figure 14: Automatic door case _ air temperature and air speed distribution in the section cross the entrance.

\section{Conclusion}

This study established the current thermal and air flow condition of a typical convenience store with an open entrance in Wales, through the site survey and monitoring work.

In addition, this study explored two potential approaches to address this particular issue to cut down associated heating bills and improve indoor comfort for a convenience store.

The heating load for the base case is $48 \mathrm{~W} / \mathrm{m}^{2} /$ year. Both an air curtain and an automatic door can significantly reduce the heating load, to $11 \mathrm{~W} / \mathrm{m}^{2} /$ year and $19 \mathrm{~W} / \mathrm{m}^{2} /$ year respectively. However, the energy demand of an air curtain can reach $1800 \mathrm{kWh} /$ year, while the total energy to run an automatic door is only $20 \mathrm{kWh} / \mathrm{year}$.

Regarding the indoor comfort, both methods can deliver higher indoor air temperatures and less cold draft. An air curtain eliminates all the cold air from entering the store, while an automatic door significantly reduces the amount of cold air entering the indoor space. In comparison, the air curtain can lead to a 2-degree increase in internal air temperature.

\section{Acknowledgement}

This study is a part of a SPECIFIC 2 LCBE demonstration project, led by the Welsh School of Architecture at Cardiff University. It's an EU-backed five-year project, funded by the European Regional Development Fund (ERDF) through the Welsh Government, InnovateUK and the Engineering and Physical Sciences Research Council (EPSRC).

\section{References}

Berner International Corporation (2008). Air Curtains: a Proven Alternative to Vestibule Design.

BRECSU \& ETSU 1996. Energy efficient refurbishment of retail buildings.

DIMPLEX (2013). The 5-month payback [Online]. Available:

http://www.modbs.co.uk/news/archivestory.php/aid/1 2535/The_5-month_payback.html] [Accessed 27/09 2016].

Faber O A P (1980). IEA Annex 1 Computer Modelling of Building Performance: Results and Analyses of Avonbank Simulation. St Albans.

Lomas K J (1994). Empirical validation of detailed thermal programs using test room data, Final report, Vol 1. International Energy Agency.

Mitsubishi Electric (2015). Air curtain helps increase energy efficiency and customer comfort [Online]. Available:

https://airconditioning.mitsubishielectric.co.uk/.../Mc Donalds_Air\%20Curtain.pdf [Accessed 27/09 2016].

Negrao C (1995). Conflation of computational 3uid dynamics and building thermal simulation. Ph.D., University of Strathclyde.

Neymark J, Judkoff R, Alexander D, Felsmann C, Strachan P, Wijsman A (2011). IEA BESTEST Multi- 
zone non-airflow in-depth diagnostic cases. Proceedings from 12th IBPSA, Sydney (Australia), 14-16 November 2011.
Wang L (2013). Investigation of the Impact of Building Entrance Air Curtain on Whole Building Energy Use. Air Curtain Study. 